\title{
Time scale analysis for fluidized bed melt granulation III: binder solidification rate
}

\author{
Kel W. Chua ${ }^{\mathrm{a}}$, Yassir T. Makkawi ${ }^{\mathrm{b}, *}$, Michael J. Hounslow ${ }^{\mathrm{a}}$
}

a Particle Products Group, Department of Chemical and Process Engineering, The University of Sheffield, Sheffield S1 3JD, United Kingdom

${ }^{b}$ Chemical Engineering and Applied Chemistry, School of Engineering and Applied Science, Aston University, Birmingham B4 7ET, United Kingdom

\section{Abstract}

In series I and II of this study, we discussed the time scale of granule-granule collision, droplet-granule collision and droplet spreading in Fluidized Bed Melt Granulation (FBMG) [Chua et al., 2010a,b]. In this third one, we consider the rate at which binder solidifies. Simple analytical solution, based on classical formulation for conduction across a semi-infinite slab, has been used to obtain a generalized equation for binder solidification time. A Multi-physics simulation package (Comsol) was used to predict the binder solidification time for various operating conditions usually considered in FBMG. The simulation results were validated with experimental temperature data obtained with a high speed infrared camera during solidification of 'macroscopic' ( $\mathrm{mm}$ scale) droplets. For the range of microscopic droplet size and operating conditions considered for a FBMG process, the binder solidification time was found to fall approximately between $10^{-3} \mathrm{~s}$ and $10^{-1} \mathrm{~s}$. This is the slowest compared to the other three major FBMG microscopic events discussed in this series (granule-granule collision, granuledroplet collision and droplet spreading).

Keywords: fluidization; granulation, simulation; binder solidification, particle processing; particle technology

* Corresponding author. +44 (0)121 204 3398; email: y.makkawi@aston.ac.uk 


\section{Introduction}

In the first paper of this series, we have identified four micro-scale rate processes active in Fluidized Bed Melt Granulation (FBMG). In series I and II, we have shown that granule-droplet is considerably fast with a time scale as fast as $10^{-5} \mathrm{~s}$ at the spray nozzle zone, while granule-granule collision at the same zone occurs at a slower rate within a time of scale $10^{-2}$ to $10^{-3} \mathrm{~s}$ (Chua et al., 2010a). The droplet spreading, however, was found to occur at a comparable rate to granule-granule and granule-droplet collision, with a time scale between $10^{-5}$ to $10^{-3} \mathrm{~s}$ (Chua et al., 2010b). In this paper, focus is made on the forth identified microscopic event, which is binder solidification. For graphical comparison between the various time scales discussed in this series, including the one presented here, the reader is referred to part I of this study (Chua et al., 2010a).

From the physical understanding of granulation in FBMG, granules are initially held together by a molten liquid bridge, which upon solidification will form stable larger diameter granule. This can only be achieved if the solidification rate is slower, or at least comparable to, the granule-granule and granule-droplet collision rates. It is also beneficial for the solidification rate to be slower than the spreading rate.

Liquid droplet solidification on solid surfaces has been studied in the past for a variety of applications, such as metallic coating, inkjet printing and painting. Due to the microscopic and fast transient nature of the process, the majority of the reported studies on droplet solidification relay on numerical simulation methods (Madejski, 1983; Bergmann et al., 2000; Kamins and Gu, 2005). Delplanque and Rangle (1997) carried out a detailed parametric study on liquid metal droplet spreading and solidification relevant to plasma spraying process. Using the classical solution to the Stefan one-dimensional solidification problem coupled with Navier-Stokes equation, the results show the predominance of solidification on the final splat size for a given range of operating conditions. Liu et al. (2004) studied the microstructural evolution of metal alloy droplets during spray forming using a model based on a population dynamic method (Zhao et al., 2002) 
coupled with heat and motion equations. The numerical model showed that smaller droplets have higher cooling rate and finer microstructure at the end of the solidification.

In FBMG, the bed temperature and droplet size are two parameters that are directly related to the binder solidification rate. Since heat transfer to the primary particle is a faster process than heat transfer to the fluidizing air, the binder solidification rate can be approximated from a heat balance between the molten binder and primary particle. Van der Scheur (1998) analyzed the effect of bed temperature and droplet size on fluidized bed granulation process and developed a heat balance model that helped in providing qualitative characterization of aggregation rate and its dependence on these two parameters.

In this paper, the main objective is to investigate the solidification rate of liquid binder in FBMG and propose a simple predictive equation that is capable of providing a reasonable estimate of the binder solidification time using simple measurable parameters. To validate the simulation model, experiments were conducted to record the temperature variations during ambient solidification of large binder droplet using an advance high speed infrared (IR) imaging technique. Similar applications of infrared imaging technique have been reported in the past; Nagashio et al. (2005) used it in monitoring the solidification behavior of Silicone melt drop, and Buffone and Sefiane (2004) used it in extracting temperature variations data during evaporative cooling of a volatile liquid.

\section{Theory}

\subsection{Simple heat conduction solution}

Assuming the surface of the granule to which the droplet is adhering is at the melting temperature of the binder, $T_{\mathrm{m}}$ the temperature profile within the granule will be given as a function of depth, $y$, by the classical result for unsteady conduction into a semi-infinite slab: 


$$
\frac{T-T_{s}}{T_{m}-T_{s}}=1-\operatorname{erf}\left(\frac{y}{\sqrt{4 \alpha t}}\right)
$$

where $\alpha$ is the thermal diffusivity in the granule $\left(\alpha=\rho_{s} C_{p s} / k_{s}\right)$ and $T_{s}$ is the initial temperature of the solid surface. The heat transferred since contact in a time $t$ is given by:

$$
\begin{aligned}
Q(t) & =A_{\mathrm{w}} \rho_{\mathrm{s}} c_{\mathrm{ps}} \int_{0}^{\infty}\left(T-T_{\mathrm{s}}\right) d y \\
& =2 A_{\mathrm{w}} \rho_{\mathrm{s}} c_{\mathrm{ps}}\left(T_{\mathrm{m}}-T_{\mathrm{s}}\right) \sqrt{\frac{\alpha t}{\pi}}
\end{aligned}
$$

where $A_{w}$ is the area of the granule that the drop wets, $\rho_{s}$ is the solid density and $C_{p s}$ is the heat capacity of the solid. Now, if we assume that the binder sensible heat is small compared to the latent heat, then the drop will solidify at a time $\tau_{s}$ when the heat transferred is equivalent to the latent heat of fusion for the binder, such that:

$$
Q\left(\tau_{s}\right)=\frac{\pi}{6} d_{o}^{3} \rho_{L} \lambda
$$

where $d_{o}$ and $\rho_{L}$ are the binder droplet diameter and density respectively. Substituting Eq. 3 in Eq. 2 yields:

$$
\tau_{s}=\frac{\pi}{\alpha}\left(\frac{\pi d_{o}^{3} \rho_{L} \lambda}{12 A_{w} \rho_{s} C_{p s}\left(T_{m}-T_{s}\right)}\right)^{2}
$$

In part II of this study (Chua et al., 2010b) we have shown that for an initial binder droplet size of $d_{o}$ the diameter of the final wetted area after spreading is linearly proportional to $d_{o}$, such that $d_{w}=K_{w} d_{o}$. The constant of proportionality, $K_{w}$, depends only on the final contact angle of the liquid binder with the spreading surface at equilibrium. Based on this, the final wetted area is given by:

$$
A_{w}=\frac{\pi}{4}\left(K_{w} d_{o}\right)^{2}
$$


Substituting Eq. 5 in Eq. 4 and re-arranging gives the solidification time, $\tau_{S}$, as follows:

$\tau_{s}=\frac{\pi}{9}\left[\frac{d_{o} \rho_{l} \lambda}{K_{w}^{2} \alpha^{0.5} \rho_{s} C_{p s}\left(T_{m}-T_{s}\right)}\right]^{2}$

For liquid Polyethylene Glycol (PEG1500) at a temperature of around $55^{\circ} \mathrm{C}, K_{w}=$ 2 (Chua et al., 2010b). Applying this to Eq. 6, we obtain:

$\tau_{s}=0.0218 X$

where

$$
X=\left[\frac{d_{o} \rho_{l} \lambda}{\alpha^{0.5} \rho_{s} C_{p s}\left(T_{m}-T_{s}\right)}\right]^{2}
$$

In the context of FMBG, the above simplified analysis might be expected to be defective in a number of respects. It might underestimate the solidification time by neglecting the finite thermal inertia of the primary particles and the sensible heat of the binder. On the contrary, however less important, the solidification time might be overestimated as a consequence of the one dimensional nature of the analysis which neglects the capacity for heat transfer in planes parallel to that of the contact. Neglect of convection to the environment may also contribute to an overestimation of the time.

\subsection{Two Dimensional numerical simulations (Comsol)}

A two-dimensional axi-symmetric simulation was carried out to estimate the binder solidification rate for a single droplet resting at equilibrium on flat or curved surfaces. Comsol Multiphysics Simulation package (Ver 3.2) was used for this purpose. The following conductive energy balance equation was solved using Finite Element Modeling:

$$
\frac{\partial T}{\partial t}=\alpha \nabla^{2} T
$$


The initial and the boundary conditions for the two cases considered are:

Case 1- droplet on flat surface (Fig. 1b):

At binder-air interface:

$\left.k \nabla T\right|_{b}=h\left(T_{b}-T_{\text {air }}\right)$

At glass-air interface:

$\left.k \nabla T\right|_{p}=0$

At the binder-flat surface interface: zero thickness

Initial conditions: $\begin{cases}T=T_{\text {hot }} & \text { Entire binder domain } \\ T=T_{\text {cold }} & \text { Entire glass domain }\end{cases}$

\section{Case 2- droplet on curved surface (Fig. 1b):}

At the binder-air and particle-air interfaces:

$\left.k \nabla T\right|_{i}=h\left(T_{i}-T_{\text {air }}\right) \quad i=b$ : binder or $p$ : particle

At the binder-curved surface (particle) interface: zero thickness

Initial conditions: $\begin{cases}T=T_{\text {hot }} & \text { Entire binder domain } \\ T=T_{\text {cold }} & \text { Entire particle domain }\end{cases}$

In the heat flux boundary, at the granule-air and droplet-air interface, the following heat transfer coefficients equations were used (Kunii and Levenspiel, 1991):

$$
\begin{array}{ll}
N u=0.03 \operatorname{Re}_{p}^{1.3} & \text { for } \operatorname{Re}_{p}=0.1-100 \\
N u=2+1.8 \operatorname{Re}_{p}^{1 / 2} \operatorname{Pr}^{1 / 3} & \text { for } \operatorname{Re}_{p}>100
\end{array}
$$

The binder thermal conductivity in the solid and liquid states is assumed independent of temperature. The specific heat capacity of PEG1500 as function 
of temperature was obtained from Differential Scanning Calorimeter (DSC) measurement conducted in the temperature range of $20-60{ }^{\circ} \mathrm{C}$ (details are given in section 3.2).

The simulation results of Case 1 are used for the model validation with experimental data. Case 2 is used to simulate the solidification of binder on a spherical particle surrounded by convective air, thus, mimicking the solidification behavior in a typical FBMG.

\section{Experiment}

\subsection{Validation experiment and procedure}

To validate the droplet solidification model, a high speed infrared (IR) thermal camera (Cedip Titanium) was used to monitor solidification of PEG1500 droplet. PEG1500 (supplied by BP Chemicals, UK) is solid at room temperature; therefore the solid flakes were heated to the desired temperature above melting in a controlled temperature reservoir using a hot plate. A flat glass plate $(10 \mathrm{~cm} \times$ $7.5 \mathrm{~cm} \times 1 \mathrm{~cm}$ ), cleaned with acetone and water and dried with lint-free tissue, was used as the spreading surface. The droplet of the melt was dispensed using a calibrated syringe, with a needle of $0.97 \mathrm{~mm}$ inside diameter, and let to fall freely from the height of $3 \mathrm{~cm}$ to the flat glass surface. Due to the experimental difficulties associated with the generation of small droplets, a larger macroscopic droplet diameter in the range of $2.0 \mathrm{~mm}$ to $4.0 \mathrm{~mm}$ was used for the model validation. Because the droplet was released from a very close distance to the glass surface, the effect of in-flight cooling was assumed negligible; this was confirmed from the IR images. The images of the droplet spreading and solidifying over the flat glass surface at ambient condition were recorded at the rate of $200 \mathrm{~Hz}$. The initial droplet temperature was in the range of $50-80^{\circ} \mathrm{C}$ and the ambient air temperature was $\sim 22{ }^{\circ} \mathrm{C}$. 


\subsection{Differential scanning calorimeter experiment}

The specific heat capacity of PEG1500 as function of temperature was obtained from DSC measurements using Perkin-Elmer Pyris1 instrument. Fig. 2 shows the result for a $4 \mathrm{mg}$ PEG 1500 cooled from $50{ }^{\circ} \mathrm{C}$ to $37{ }^{\circ} \mathrm{C}$ at a cooling rate of 0.5 ${ }^{\circ} \mathrm{C} / \mathrm{min}$. The peak of specific heat capacity between $41-44^{\circ} \mathrm{C}$ is an indication of the phase change behavior due to solidification. This data was used to derive a relation between the specific heat capacity and temperature, which was then applied in the solution of the 2D Comsol simulation model.

\section{Experimental validation of Comsol predictions}

Prior to experimental validation, the model sensitivity to grid size was evaluated in order to ensure grid independence solution. Table 1 shows the grid cases considered in the analysis along with the corresponding computational time. The simulation parameters are the default ones given in Table 2. The progression of temperature, expressed here in terms of the maximum temperature within the droplet domain, is plotted against time in Fig. 3. The temperature profiles for the case "Fine" and the case "Extra Fine" are almost identical despite the considerable difference in the computational time. Therefore, the following simulations were carried out using "Fine" grid settings.

A sequence of snapshot images of the evolution of binder droplet solidification on a flat glass surface was used for qualitative validation of the numerical simulation. As shown in Fig. 4, there is a good qualitative agreement. It can also be seen that the droplet stays hot at the core while the edges cool progressively and the solidification front moves from the binder-glass interface towards the top of the droplet. The significant observation in a granulation context is that the droplet tip remains active for longer time, this enhance the probability of successful aggregation between two colliding particles in FBMG.

Fig. 5 shows a comparison between experimentally measured solidification time and the model predictions for various initial droplet diameters. In this analysis, the 
droplet is considered to be fully solidified when the temperature at all points within the droplet domain has dropped below the PEG1500 solidifying temperature, $\sim 44{ }^{\circ} \mathrm{C}$. Clearly, the simple analytical model of Eq 7 dramatically under predicts the solidification time. Never-the-less the solidification time prove to be linearly proportional to $X$, as suggested by Eq. 7. We also observe that the Comsol predictions are quantitatively in good agreement with the experimental measurements.

\section{Binder solidification time in FBMG}

Having now confirmed the validity of the numerical simulation model, a series of simulations for a range of operating conditions usually considered in FBMG were conducted. The simulations were considered for the case of binder solidifying on a spherical particle (case 2 in section 2.2). The range of operating conditions and the physical properties of the glass particles and binder used in the simulations are shown in Table 3.

Fig. 6 shows the Comsol-predicted solidification time as function of the parameter $X$. For the range of conditions considered here, the numerical simulation results show that the solidification time is in the range of $10^{-3} \mathrm{~s}$ to $10^{-1}$ s. The data shown in Fig. 6 also suggests that the analytical model of Eq. 7 is correct in terms of proportionality to parameter $X$, but for a constant of 0.127 rather than the originally suggested value of 0.0218 . Thus for the special case of PEG1500 under the operating conditions given in Tables 2 and 3, the correct version of Eq. 7 would be:

$\tau_{s}=0.127 X$

We mainly attribute this difference to neglect of binder sensible heat. For example if the heat capacity data of Fig 2 are integrated from 27.8 to $60{ }^{\circ} \mathrm{C}$, the specific heat dissipated is $247.8 \mathrm{~kJ} / \mathrm{kg}$, which would reduce the constant of 
proportionally to 0.0496 . The remaining discrepancy we attribute to the other defects discussed earlier in section 2.1.

Recalling the results discussed in part I and II of this study (Chua et al., 2010a,b), it is clear that the time scale for granule-droplet collision and droplet spreading are relatively fast. The longer solidification time predicted here implies high probability of successful aggregation, and hence improved FBMG efficiency.

To investigate the effect of the bed temperature on the binder solidification rate, Comsol simulation of droplet solidification for various surrounding air temperature has been carried out and the result is plotted against the solidification time in Fig. 7. As is evident, the fluidized bed temperature plays a major role in the solidification rate. It is believed that the solidification behavior in FBMG is controlled by two heat transfer mechanisms; conduction through the particle at low bed temperature and forced convection to the surrounding fluidizing air at high bed temperature. In the later case, the particles are first heated by the fluidizing air; as a result, the binder solidification process slows down dramatically because primary particles become thermally saturated before the binder solidifies. Consequently, instead of conduction, the partially solidified binder has to be cooled via air convection which is relatively slow compared to conduction cooling at the granule surface. In the first case, the primary particle is cold and hence, the solidification process is dominated by rapid heat conduction through the particle.

\section{Conclusion}

In this paper the solidification time of binder droplets in FBMG processes has been determined using two different approaches; simple analytical solution for heat transfer into a semi-infinite slab and Comsol numerical simulation.

The numerical simulations have shown that for the range of operating conditions considered here the solidification rate for PEG1500 binder is in the range of $10^{-3}$ 
$\mathrm{s}$ to $10^{-1} \mathrm{~s}$. Compared to the other microscopic events studied in this series, the average solidification time is the slowest. The simulation also shows that the solidification time increases rapidly with increasing the fluidized bed temperature.

The analytical solution revealed that the solidification time can be linearly related to a simple operational parameter expressed in terms of the binder and spreading surface physical properties, the temperature gradient between the binder and solidifying surface and final wetted area. However the constant of proportionality for use with this analytical model needs to be determined experimentally or by means of a more complex simulation. The Comsol simulations used in this study are shown to be quantitatively correct by means of a set of macroscopic verification experiments.

The solidification time scale presented here along with the time scales discussed in Part I and II of this study (Chua et al., 2010a,b) indicates that insight to microscopic granulation behavior can be obtained from theoretical analysis. For a given binder and fluidized bed operating condition, such information can lead to full optimization of the process and provide a tool for qualitative and quantitative description of the overall aggregation process. A comparison of the four time scales studied in this series can be found in part I of this study (Chua et al., 2010a). In the final paper in this series we show how knowledge of the four time scales can be used to predict the rate of aggregation in a FBMG process. 


\section{Notation}

$A_{w} \quad$ wetted area $\left(\mathrm{m}^{2}\right)$

$C_{p s} \quad$ specific heat capacity of solid $\left(\mathrm{Jkg}^{-1}{ }^{\circ} \mathrm{C}^{-1}\right)$

$d_{0} \quad$ initial droplet diameter ( $\left.\mathrm{m}\right)$

$d_{w} \quad$ final spreaded area diameter $(\mathrm{m})$

$h \quad$ heat transfer coefficient $\left(\mathrm{kg} \mathrm{m}^{-1} \mathrm{~s}^{-1}\right)$

$K_{w} \quad$ parameter defined in Eq. 5 (-)

$k \quad$ effective thermal conductivity $\left(\mathrm{kg} \mathrm{m}^{-1} \mathrm{~s}^{-1}\right)$

$\mathrm{Nu} \quad$ Nusselt number (-)

Pr Prandtl number (-)

Q heat transferred (J)

$\mathrm{Re}_{p} \quad$ particle Reynolds number (-)

$t$ time (s)

$T$ instantaneous temperature $\left({ }^{\circ} \mathrm{C}\right)$

$T_{s} \quad$ solid temperature at cooling surface $\left({ }^{\circ} \mathrm{C}\right)$

$T_{m} \quad$ melting temperature of binder $\left({ }^{\circ} \mathrm{C}\right)$

$X \quad$ parameter defined in Eq. 7a (s)

$y \quad$ depth $(\mathrm{m})$

Greek symbols

$\tau_{s} \quad$ solidification time (s)

$\tau_{w} \quad$ spreading time (s)

$\alpha \quad$ thermal diffusivity $\left(\mathrm{m}^{2} \mathrm{~s}^{-1}\right)$

$\mu \quad$ viscosity $\left(\mathrm{N} \mathrm{m}^{-2} . \mathrm{s}\right)$

$\rho \quad$ density $\left(\mathrm{kg} \mathrm{m}^{-3}\right)$

$\lambda \quad$ latent heat of fusion $\left(\mathrm{J} \mathrm{kg}^{-1}\right)$

\section{Subscripts}

$b \quad$ binder

$l \quad$ liquid phase (molten binder)

$p \quad$ particle

$s \quad$ solid phase (primary particle) 


\section{References}

Bergmann, D., Fritsching, U., Bauckhage, K., 2000. A mathematical model for cooling and rapid solidification of molten metal droplets. International Journal of Thermal Sciences. 39, 53 - 62.

Buffone, C. and Sefiane, K., 2004. IR measurements of interfacial temperature during phase change in a confined environment. Experimental Thermal and Fluid Science 29, 65-74.

Delplanque, J. P., Rangel, R. H., 1997. An improved model for droplet solidification on a flat surface. Journal of Materials Science, 32, 1519-530.

Chua, Kel W., Makkawi, Y. T., Hounslow, M. J., 2010a. Time scale analysis for fluidized bed melt granulation I: granule-granule and granule-droplet collision rates. Chemical Engineering Science, submitted.

Chua, Kel W., Makkawi, Y. T., Hounslow, M. J., 2010b. Time scale analysis for fluidized bed melt granulation II: binder spreading rate. Chemical Engineering Science, submitted.

Kamins, S., Gu, S., 2005. Numerical Modeling of droplet impingement, Journal of Physics D Applied Physics. 38, 3664 - 3673.

Kunii, D., Levenspiel, O., 1991. Fluidization Engineering (2 ${ }^{\text {nd }}$ Ed.). London, Butterworth-Heinemann.

Liu, D., Zhao, J., Ye, H., 2004. Modeling of the solidification of gas-atomized alloy droplets during spray forming. Materials Science and Engineering, 372, 229-234.

Madejski, J., 1983. Droplets on impact with a solid surface Int. J. Heat Mass Transfer, 26, $1098-1102$.

Nagashio, K., Murata, H., Kuribayashi, K., 2005. In situ observation of solidification behavior of $\mathrm{Si}$ melt dropped on $\mathrm{Si}$ wafer by IR thermography. Journal of Crystal Growth, 275, 1685-1690.

Van der Scheur, F., Goedendorp, P., Goot, A. van der, Olieman, J., 1998. Fluidised bed agglomeration with polyethylene glycol melt binder: effects of bed 
temperature and droplet size. Proc. of World congress of Particle Technology 3 , 103.

Zhao, J., Ratke, L., Jia, J., Li, Q., 2002. Modeling and simulation of the microstructure evolution during a cooling of immiscible alloys in the miscibility gap. J. Mater. Sci. Technol., 18, 197-205. 


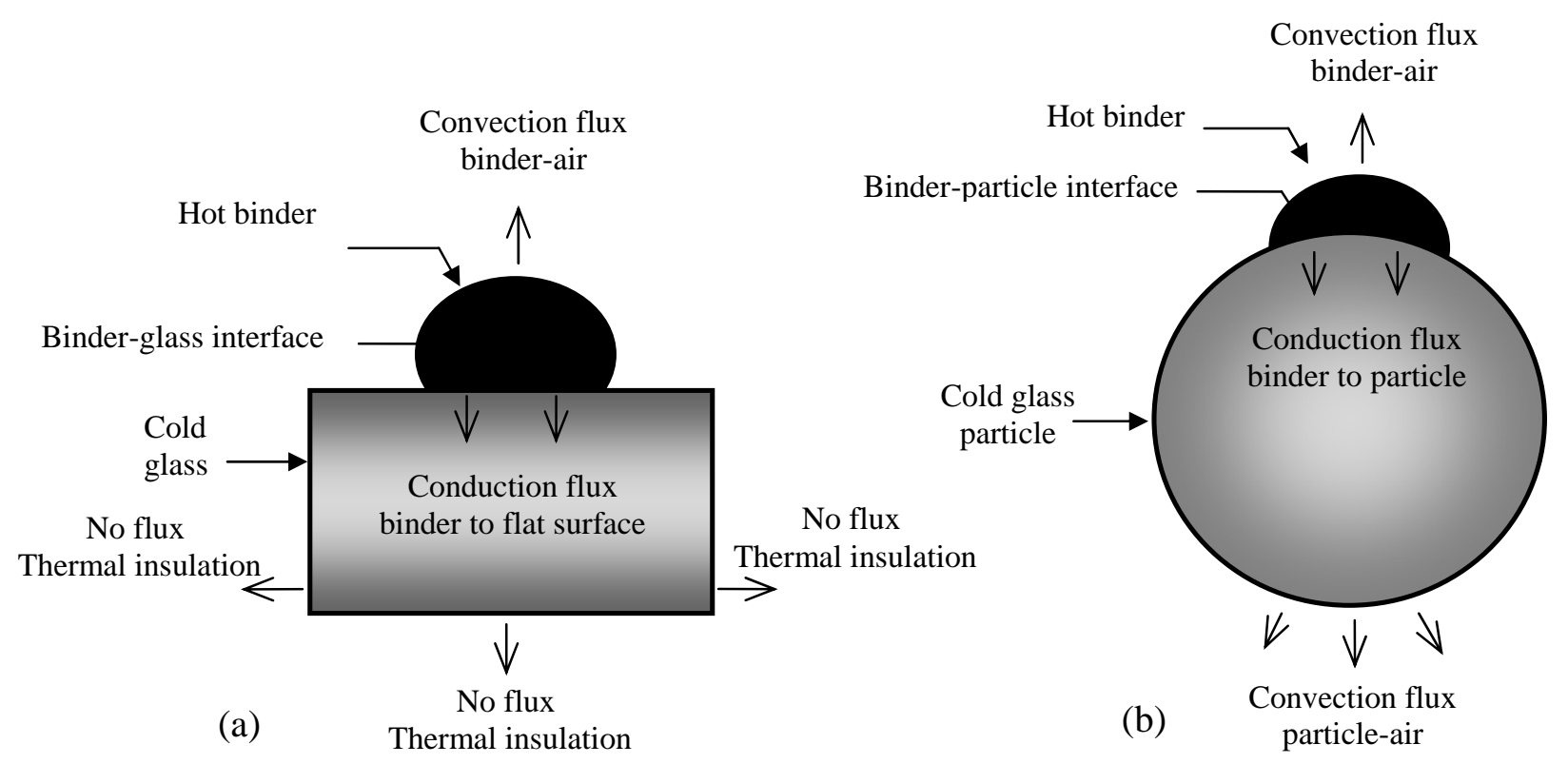

Fig. 1. Schematic representation of binder droplet solidification mechanisms and the boundary conditions used in the Comsol simulation models. 


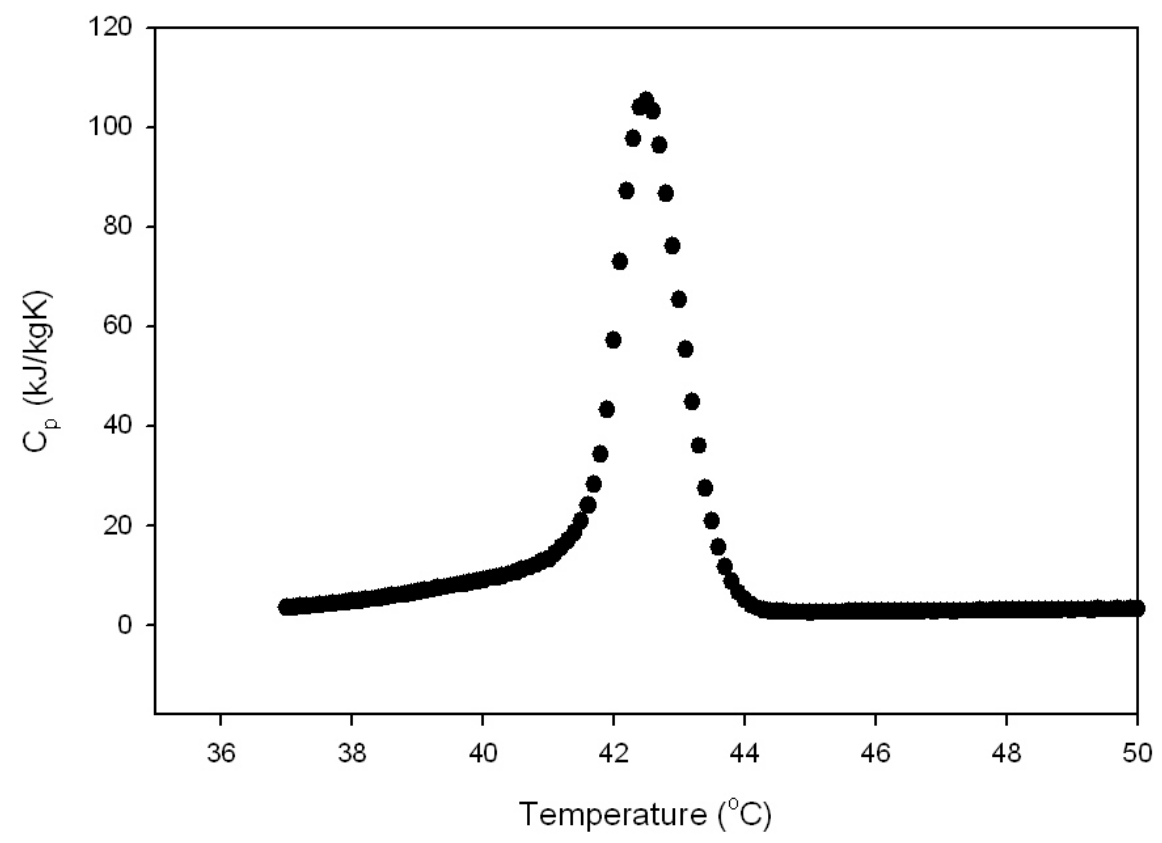

Fig. 2. Specific heat capacity of PEG1500 as function of temperature obtained from DSC measurements. 


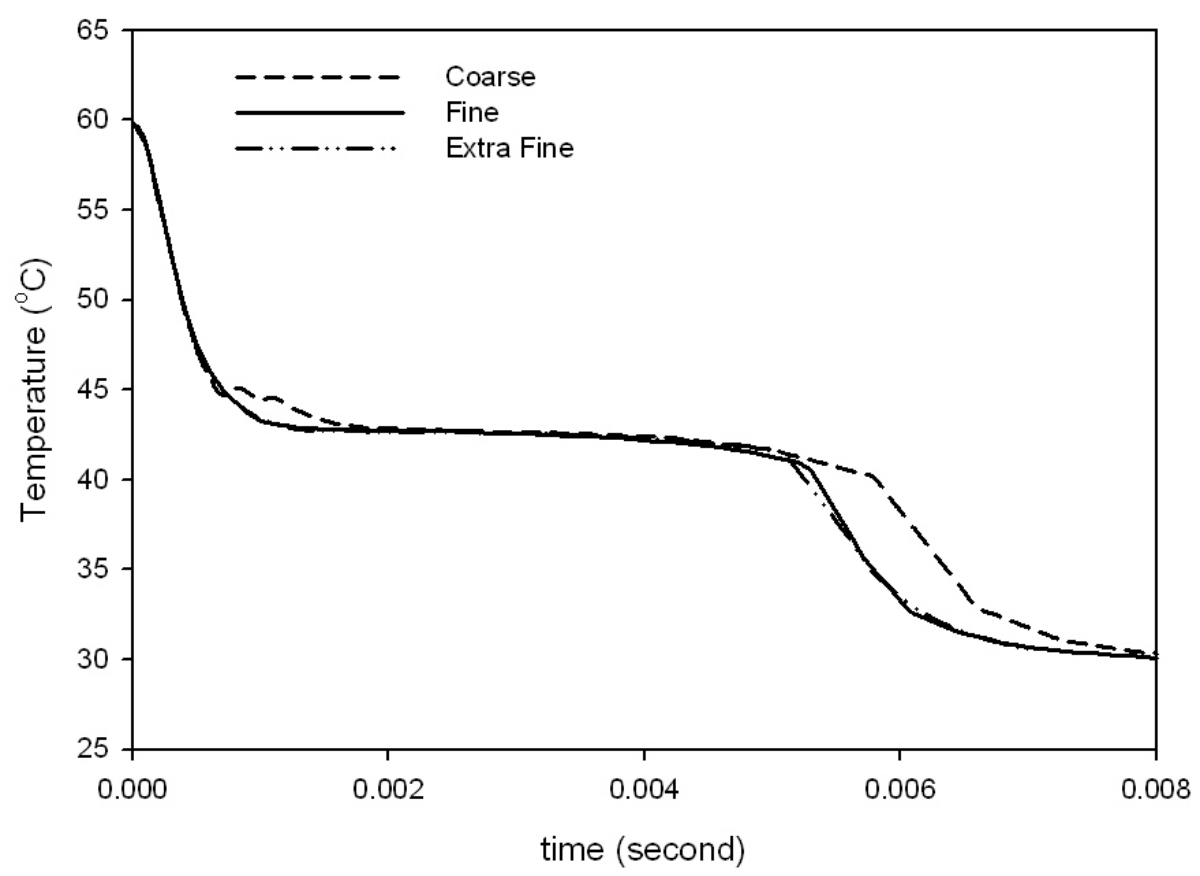

Fig. 3. Test on Comsol simulation sensitivity to grid size carried out for a $40 \mu \mathrm{m}$ PEG1500 droplet solidifying on a spherical particle of $120 \mu \mathrm{m}$ at a surrounding air and particle temperatures of $27.8^{\circ} \mathrm{C}$. Other simulation parameters are given in Table 2. 


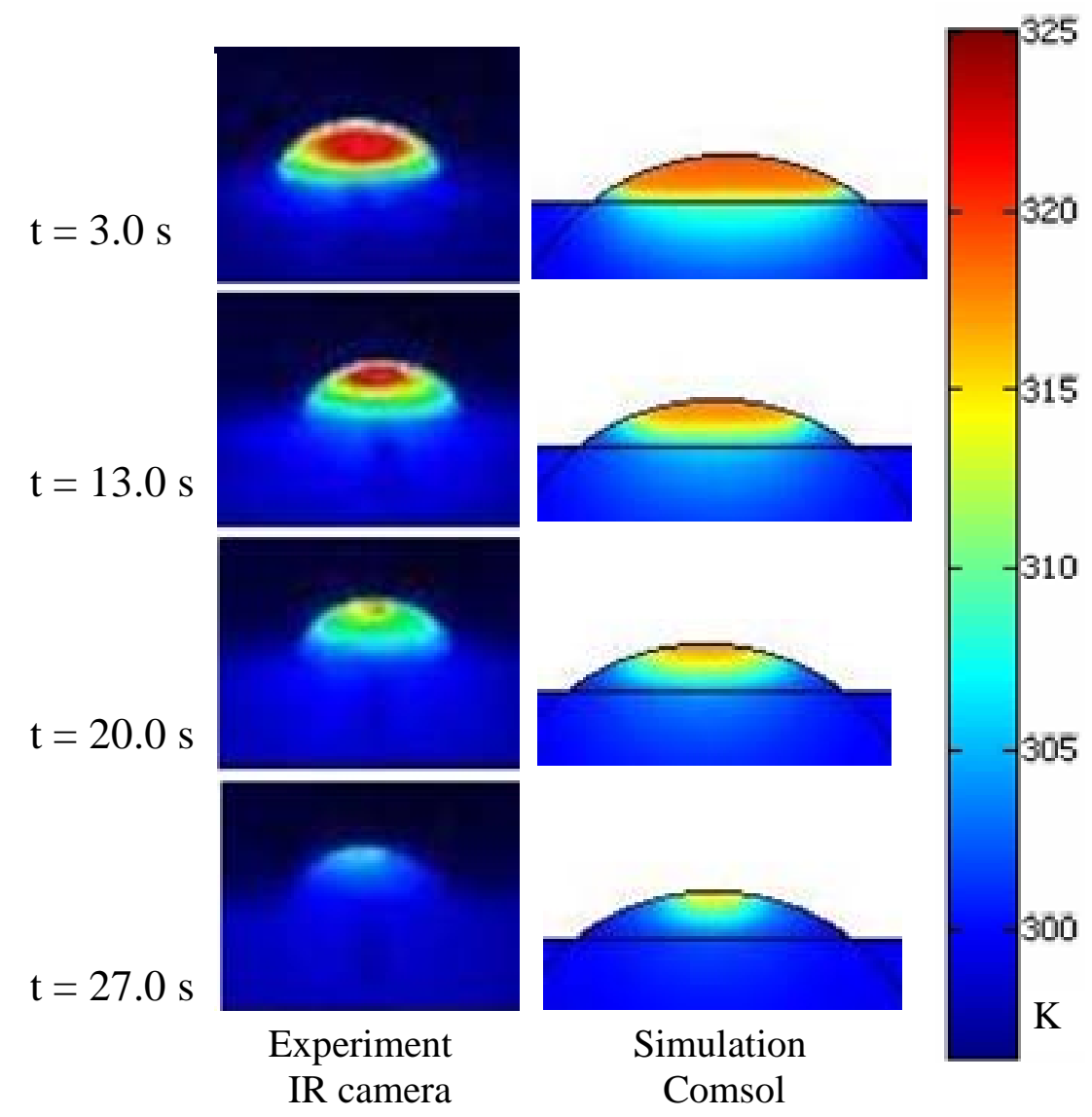

Fig. 4. Comparison of temperature contours from experiment and Comsol simulation of PEG1500 droplet solidification. Initial droplet temperature $51.8{ }^{\circ} \mathrm{C}$, glass surface temperature $24.8^{\circ} \mathrm{C}$ and initial droplet diameter $3.0 \mathrm{~mm}$. Simulation parameters are given in Table 2 . 


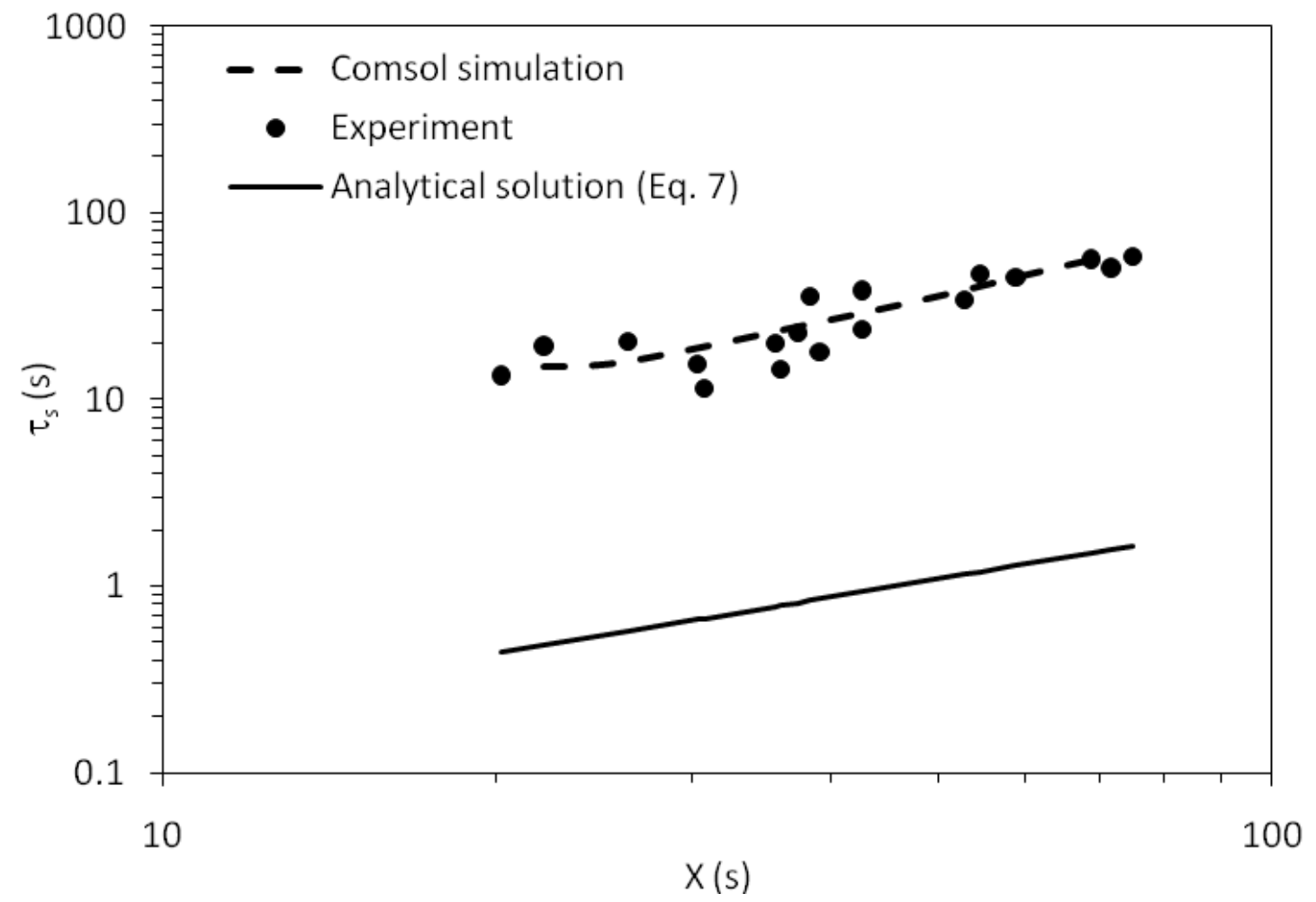

Fig. 5. Experimental and model predictions of PEG1500 droplet solidification time as function of the initial droplet diameter. Droplet solidifying on a flat glass surface at $25{ }^{\circ} \mathrm{C}$, initial droplet temperature of $70{ }^{\circ} \mathrm{C}$. Detailed simulation parameters are given in Table 2 . 


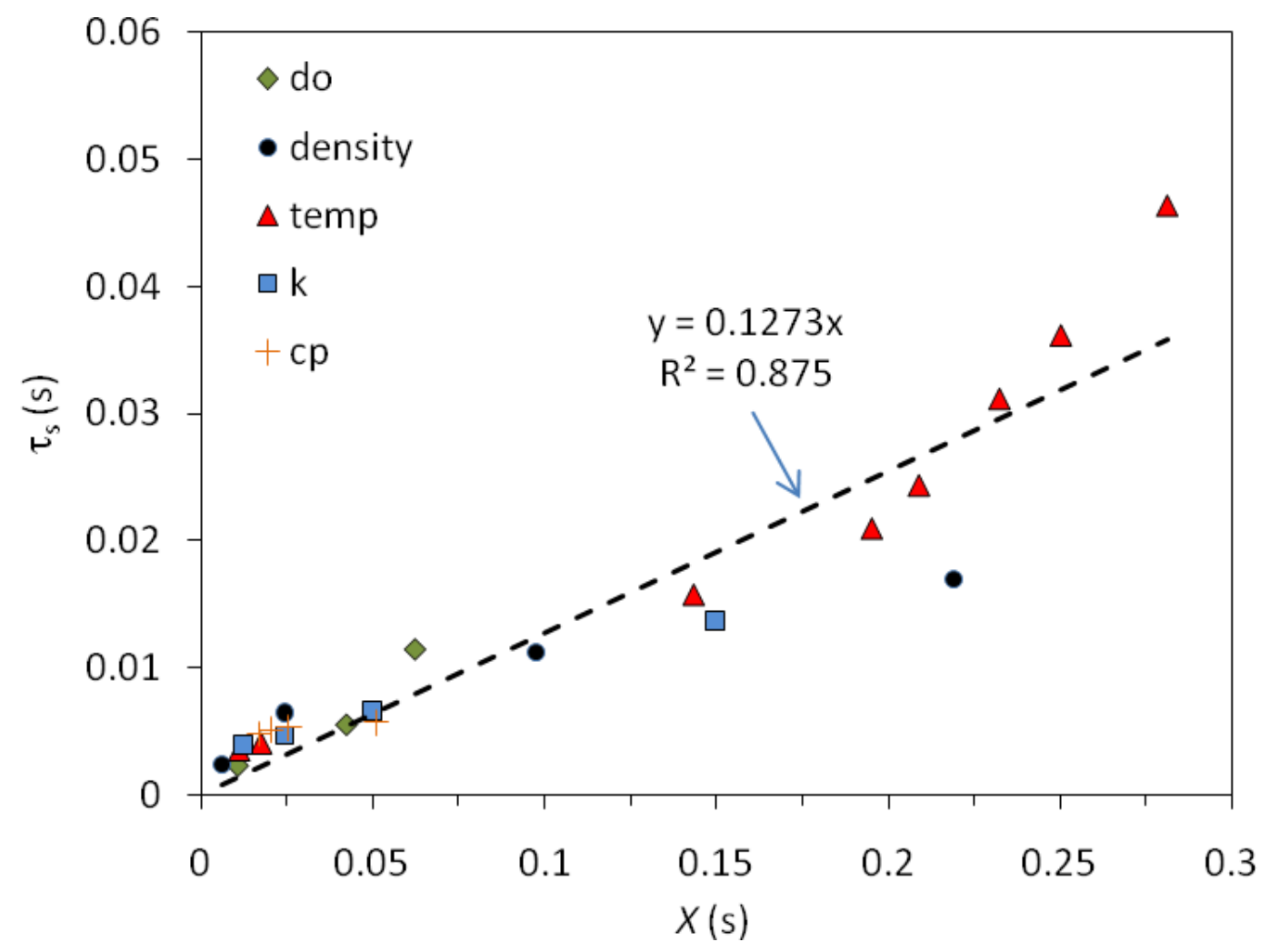

Fig. 6. Binder solidification time in FBMG for various operating conditions expressed in terms of the parameter $X$. The symbols represent Comsol predictions, the dotted line is the linear fitting of the Comsol data. Key for the symbols and operating condition ranges are given in Table 3. Other simulation parameters are given in Table 2. 


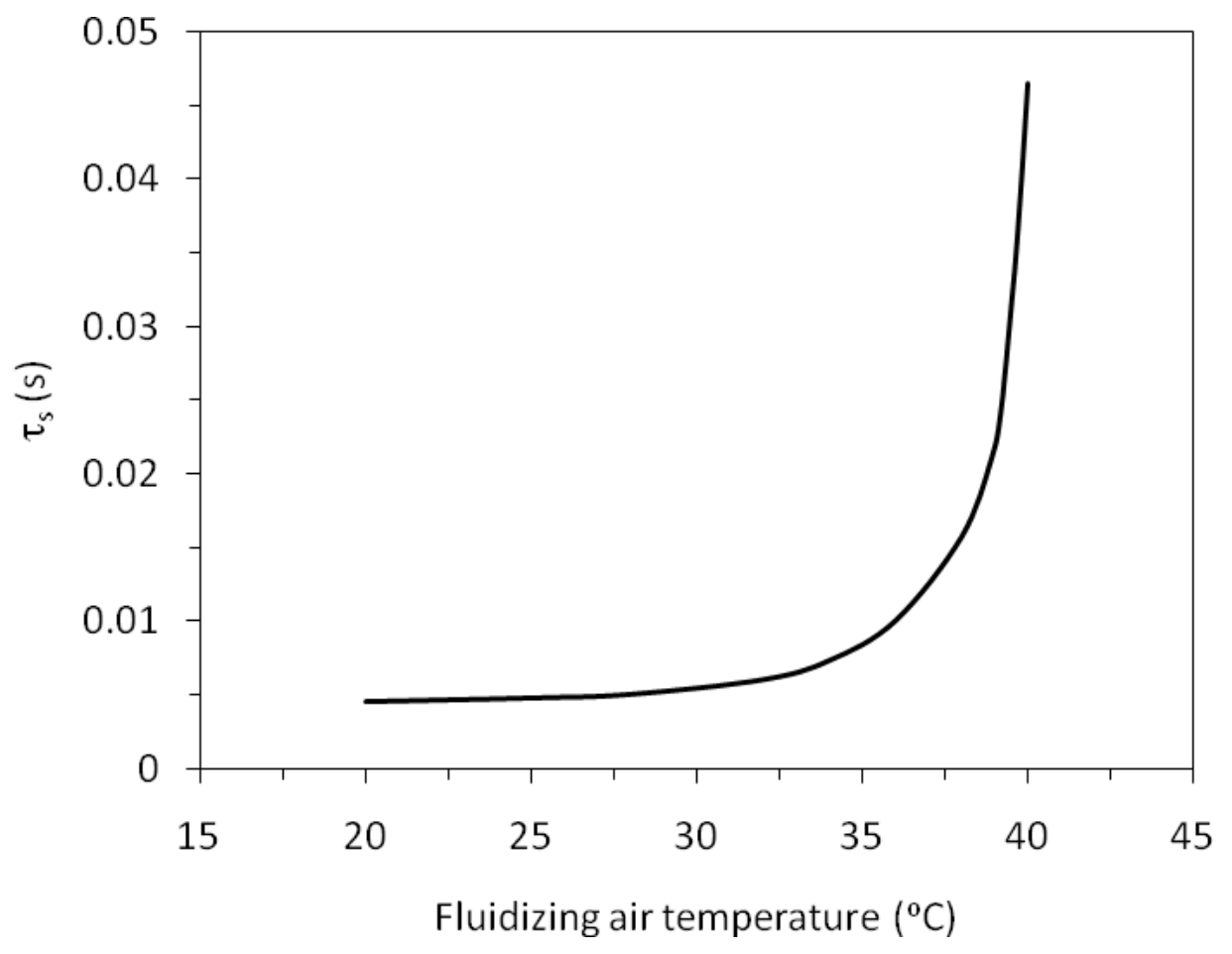

Fig. 7. Comsol predictions of PEG1500 binder solidification time in FBMG as function of the fluidizing air temperature. Initial binder droplet temperature is 70 ${ }^{\circ} \mathrm{C}$ and the droplet and primary particle sizes are $40 \mu \mathrm{m}$ and $120 \mu \mathrm{m}$ respectively. Other simulation parameters are given in Table 2. 
Table 1. Grid test for solidification model

\begin{tabular}{c|c|c}
\hline Case & $\begin{array}{c}\text { Element } \\
\text { (cells) }\end{array}$ & $\begin{array}{c}\text { Computation time } \\
(\mathrm{s})\end{array}$ \\
\hline Coarse & 3,968 & 82.5 \\
Fine & 7,640 & 113.4 \\
Extra Fine & 15,5160 & 2711.5 \\
\hline
\end{tabular}

Table 2. Default physical properties used in the simulation of binder solidification

\begin{tabular}{l|l}
\hline Simulation variables & Range \\
\hline Solid surface thermal conductivity, $k_{s}(\mathrm{~W} / \mathrm{mK})$ & 1.23 \\
Solid surface specific heat capacity, $C_{p s}(\mathrm{~J} / \mathrm{kgK})$ & 840 \\
Solid density, $\rho_{s}\left(\mathrm{~kg} / \mathrm{m}^{3}\right)$ & 2500 \\
Binder density, $\rho_{l}\left(\mathrm{~kg} / \mathrm{m}^{3}\right)$ & 1093 \\
Binder specific heat capacity, $C_{p l}(\mathrm{~J} / \mathrm{kgK})$ & See Fig. 2 \\
Binder thermal conductivity, $k_{l}(\mathrm{~W} / \mathrm{mK})$ & 0.23 \\
Binder latent heat of fusion, $\lambda(\mathrm{kJ} / \mathrm{kg})$ & 155.0 \\
Binder melting temperature $\left({ }^{\circ} \mathrm{C}\right)$ & 44.0 \\
\hline
\end{tabular}

Table 3. Parameters used in the simulation of binder droplet solidification time shown in Fig. 7.

\begin{tabular}{l|c|c|c|c|c}
\hline & $\bullet$ & $\square$ & + & $\Delta$ & $\diamond$ \\
\hline Binder density, $\rho_{l}\left(\mathrm{~kg} / \mathrm{m}^{3}\right)$ & $1093-3550$ & 1093 & 1093 & 1093 & 1093 \\
Particle thermal conductivity, $k_{s}(\mathrm{~W} / \mathrm{mK})$ & 1.23 & $0.2-6$ & 1.23 & 1.23 & 1.23 \\
Air temperature, $T_{o}\left({ }^{\circ} \mathrm{C}\right)$ & 27.8 & 27.8 & 27.8 & $20-40$ & 27.8 \\
Solid specific heat capacity, $C_{p l}(\mathrm{~J} / \mathrm{kgK})$ & 840 & 840 & $400-1200$ & 840 & 840 \\
Binder droplet diameter, $d_{o}(\mu \mathrm{m})$ & 40 & 40 & 40 & 40 & $16-40$ \\
\hline
\end{tabular}

